OPEN ACCESS

Edited by: Scott Levick,

The University of Sydney, Australia

Reviewed by:

Augie Pioszak,

University of Oklahoma Health

Sciences Center, United States

Jan Danser,

Erasmus Medical Center, Netherlands

*Correspondence:

Fulye Argunhan

fulye.argunhan@kcl.ac.uk

Specialty section:

This article was submitted to

Vascular Physiology,

a section of the journal

Frontiers in Physiology

Received: 11 December 2021

Accepted: 21 January 2022

Published: 25 February 2022

Citation:

Argunhan F and Brain SD (2022)

The Vascular-Dependent

and -Independent Actions

of Calcitonin Gene-Related Peptide

in Cardiovascular Disease.

Front. Physiol. 13:833645.

doi: 10.3389/fphys.2022.833645

\section{The Vascular-Dependent and -Independent Actions of Calcitonin Gene-Related Peptide in Cardiovascular Disease}

\author{
Fulye Argunhan* and Susan D. Brain
}

Section of Vascular Biology \& Inflammation, School of Cardiovascular Medicine \& Research, BHF Centre of Excellence, King's College London, London, United Kingdom

The treatment of hypertension and heart failure remains a major challenge to healthcare providers. Despite therapeutic advances, heart failure affects more than 26 million people worldwide and is increasing in prevalence due to an ageing population. Similarly, despite an improvement in blood pressure management, largely due to pharmacological interventions, hypertension remains a silent killer. This is in part due to its ability to contribute to heart failure. Development of novel therapies will likely be at the forefront of future cardiovascular studies to address these unmet needs. Calcitonin gene-related peptide (CGRP) is a 37 amino acid potent vasodilator with positive-ionotropic and chronotropic effects. It has been reported to have beneficial effects in hypertensive and heart failure patients. Interestingly, changes in plasma CGRP concentration in patients after myocardial infarction, heart failure, and in some forms of hypertension, also support a role for CGRP on hemodynamic functions. Rodent studies have played an important role thus far in delineating mechanisms involved in CGRP-induced cardioprotection. However, due to the short plasma half-life of CGRP, these well documented beneficial effects have often proven to be acute and transient. Recent development of longer lasting CGRP agonists may therefore offer a practical solution to investigating CGRP further in cardiovascular disease in vivo. Furthermore, pre-clinical murine studies have hinted at the prospect of cardioprotective mechanisms of CGRP which is independent of its hypotensive effect. Here, we discuss past and present evidence of vasculardependent and -independent processes by which CGRP could protect the vasculature and myocardium against cardiovascular dysfunction.

Keywords: CGRP, cardiovascular, heart, mouse, nitric oxide, hypertension, heart failure

\section{INTRODUCTION}

The discovery of Calcitonin gene-related peptide (CGRP) mRNA in the rat hypothalamus by Amara et al. (1982) sparked a series of studies exploring the effect of CGRP in the central and peripheral systems, where it is widely distributed. The authors discovered that human CALCA gene, which codes for the thyroid gland hormone calcitonin, can also produce CGRP via alternative splicing in neural tissues. CGRP is a member of the calcitonin family of peptides, that include adrenomedullin, 
adrenomedullin 2/intermedin and amylin (Russell et al., 2014). Soon after, it was found that CGRP has two structurally similar isoforms - the $\alpha$ and $\beta$, which are encoded by two distinct genes (Amara et al., 1985). Both isoforms are primarily located in sensory C- and A $\delta$-fibers (Gibson et al., 1984), and it is generally accepted that despite $94 \%$ sequence identity between the two isoforms, $\beta$-CGRP synthesis and expression is concentrated around the enteric nervous system, immune cells and pituitary gland (Steenbergh et al., 1985; Brain and Grant, 2004) whereas $\alpha$-CGRP is primarily involved in the central and peripheral nervous systems, and consequently, is the more extensively studied isoform in cardiovascular studies. This review aims to discuss past and present literature on CGRP in hypertension and heart failure to stimulate thought on the future of CGRP and cardiovascular research, with a particular focus on $\alpha$-CGRP.

The current consensus is that, upon neuronal depolarization, $\alpha$ - or $\beta$-CGRP is released from sensory neurons via calciumdependent exocytosis to bind to its receptor situated on the plasma membrane of several cell types including, but not limited to, smooth muscle cells (Argunhan et al., 2021), endothelial cells (Gray and Marshall, 1992a) and cardiomyocytes (Clark et al., 2021). The receptor complex is composed of a seven domain G-protein coupled receptor (GPCR) known as calcitonin receptor-like receptor (CRLR) and a single transmembrane protein recognized as receptor activity modifying protein-1 (RAMP1). RAMP1 is required for trafficking of the receptor to the cell surface to form a heterodimer with CRLR and mediate high-affinity binding to CGRP. Upon activation of the CRLR/RAMP1 receptor, G-protein induced signaling cascade is initiated, with $\mathrm{G} \alpha_{s}$-induced cyclic adenosine monophosphate (cAMP) being the major secondary messenger involved (McLatchie et al., 1998; Pioszak and Hay, 2020). The CGRP family of receptors also comprise two other RAMP proteins; RAMP2 and RAMP3. There is evidence that CGRP may be able to signal via receptors including these components. The receptors involved comprise the calcitonin receptor (CTR) interacting with RAMP1, commonly called the amylin receptor and CRLR interacting with RAMP2, the adrenomedullin receptor (Hay et al., 2018). The selectivity of CGRP for receptors other than CRLR/RAMP1 is under investigation.

Due to the CRLR/RAMP1 receptor complex being expressed in the plasma membrane of smooth muscle cells and endothelial cells, CGRP-induced vasodilation can manifest via two distinct but related mechanisms. The CGRP ligand can bind directly to the receptor complex in vascular smooth muscle cells to induce PKA-mediated smooth muscle relaxation, or it can interact with its receptor complex in endothelial cells to induce endothelialdependent relaxation via nitric oxide signaling (Crossman et al., 1990; Gray and Marshall, 1992b). In vascular smooth muscle cells, CGRP-induced PKA phosphorylation leads to: reduced intracellular $\mathrm{Ca}^{2+}$ concentration; reduced binding affinity of myosin light chain kinase (MLCK) to $\mathrm{Ca}^{2+}$-calmodulin complex; and activation of ion channels such as ATP-sensitive potassium channels $\left(\mathrm{K}_{\mathrm{ATP}}\right)$. All of these contribute to smooth muscle cell relaxation, and thus vasodilation (Brain and Grant, 2004; Figure 1A). In endothelial cells, PKA phosphorylation of eNOS results in NO generation, which is known to diffuse into neighboring vascular smooth muscles and mediate smooth muscle cell relaxation via guanyl cyclase and protein kinase G (PKG) signaling induction pathways (Russell et al., 2014; Figure 1A). Additionally, there is some evidence for PKCmediated responses post-CGRP receptor activation (Walker et al., 2010) but the cAMP response is the most established and understood signaling pathway to date. However, it is important to acknowledge the body of in vitro evidence suggesting that the CGRP receptor can couple with other G proteins (Weston et al., 2016). It is also noteworthy that, in addition to its canonical receptor, CGRP has been shown to interact with other receptors from the CGRP family of peptides, albeit with lower affinity (Hay et al., 2018). Recently, the structure and dynamics of the canonical CGRP receptor has been investigated using singleparticle cryo-EM (Liang et al., 2018; Josephs et al., 2021), and agonist bias studies have revealed physiological consequences for the CRLR-RAMP1 complex in different cell types (Clark et al., 2021). Thus, this is an area of much interest that is continually evolving, with RAMP proteins being the subject of investigation.

\section{CALCITONIN GENE-RELATED PEPTIDE AND VASCULAR TONE - SMALL BUT MIGHTY}

Fisher et al. (1983) were the first to demonstrate the hypotensive effects of systemically administered CGRP in rats, whereas Brain et al. (1985, 1986) showed that intradermal injection of CGRP at femtomole doses induces arteriole dilation, thus increasing blood flow locally in animal and human skin. These studies and others indicated that CGRP is a potent vasodilator, leading researchers to further explore its beneficial potential within the cardiovascular system. As a microvascular vasodilator, the potency of CGRP is approximately 10-fold higher than prostaglandins, up to 100 times greater than other well-established vasodilators such as acetylcholine, thus making CGRP the most potent peripheral vasodilator discovered to date (Russell et al., 2014).

Gennari and Fischer (1985) were first to determine the cardiovascular actions of CGRP on hemodynamic parameters in healthy humans. In addition to CGRP's intrinsic ability to cause vasodilation and consequently hypotension, the authors revealed that CGRP possesses positive chronotropic and inotropic activities. CGRP was reported to increase the force of contractility by stimulating the sympathetic nervous system, which was further supported by Gennari et al. (1990) when patients with congestive heart failure (CHF) demonstrated improved cardiac contractility after receiving $\beta$-CGRP infusion for $24 \mathrm{~h}(12.5 \mathrm{ug} / \mathrm{h})$. Ex vivo experiments reinforce these findings, although the mechanism behind the positive inotropic effect is still to be fully elucidated. Franco-Cereceda et al. (1987) were the first to report the effect of CGRP treatment in isolated human auricles, and interestingly, the authors found both $\alpha$ - and $\beta$ - isoforms of CGRP to be equally potent in affecting positive inotropy.

Similarly, Struthers et al. (1986) infused hCGRP into healthy patients (545 $\mathrm{pmol} / \mathrm{min})$, which, as expected, caused a significant 

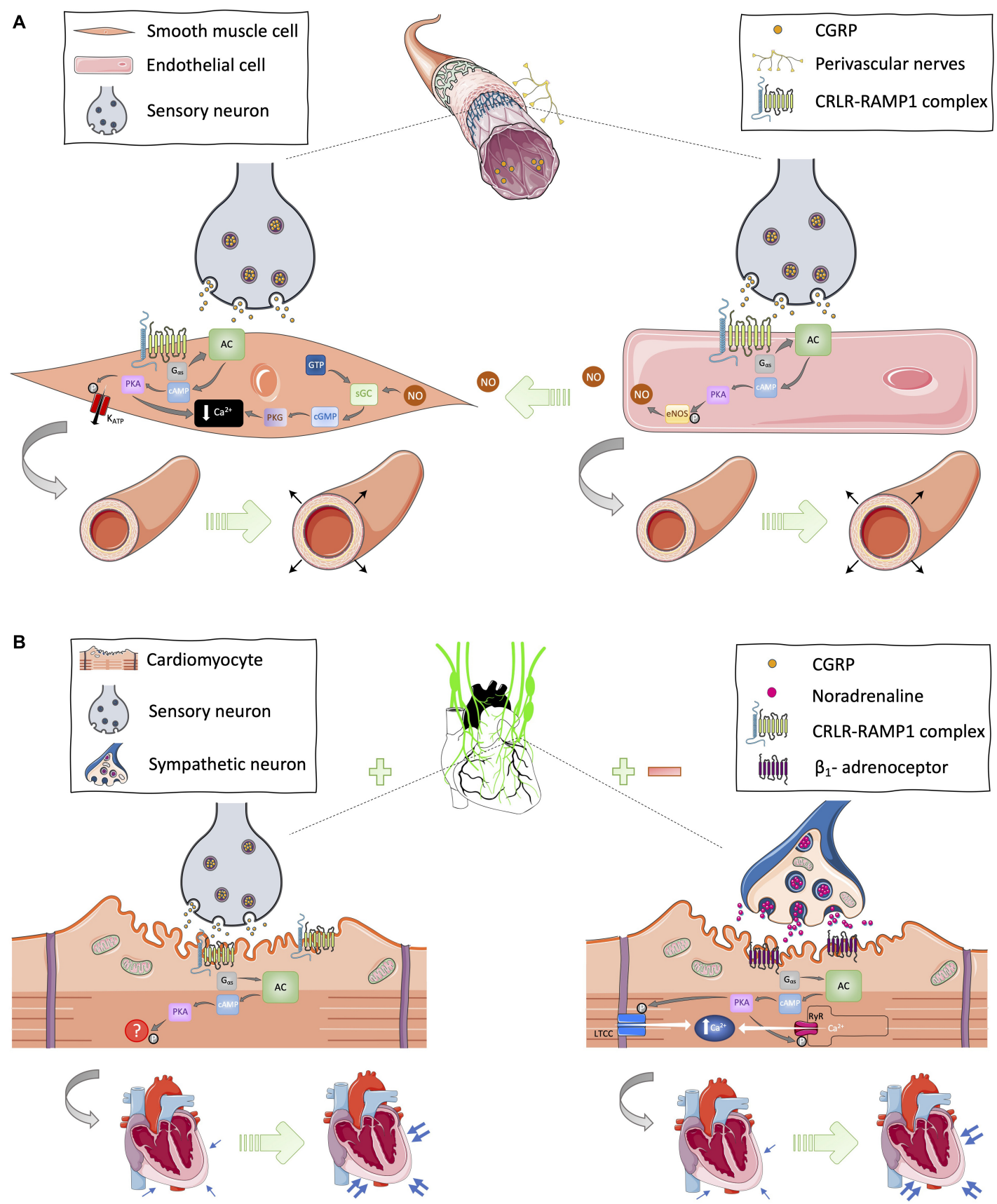

FIGURE 1 | Proposed cardioprotective mechanisms of CGRP in the (A) vasculature and (B) myocardium. (A) In the vasculature, CGRP circulating in the blood or released from sensory neurons can bind on to its canonical receptor, the CRLR-RAMP1 complex, expressed in the plasma membrane of vascular smooth muscle and endothelial cells to initiate $\mathrm{G} \alpha_{s}$-protein signal transduction and subsequently cause relaxation of smooth muscle cells via nitric oxide (NO)-dependent and -independent mechanisms thus leading to vasodilation. (B) In cardiac tissues, there is evidence for CGRP-stimulated modulation of sympathetic outflow and expression of the CRLR-RAMP1 complex on cardiomyocytes. Hence, CGRP has the potential to induce G $\alpha_{s}$-protein signaling from sensory and sympathetic nerves leading to increased cardiac contractility, thus positive inotropy and chronotropy. AC, adenyl cyclase; CAMP, cyclic adenosine monophosphate; cGMP, cyclic guanosine monophosphate; eNOS, endothelial nitric oxide synthase; GTP, guanosine triphosphate; KATP, ATP-sensitive potassium channels; LTCC, L-type calcium channel; NO, nitric oxide; P, phosphate; PKA, protein kinase A; RyR, ryanodine receptor; sGC, soluble guanylate cyclase. [Images were obtained from smart.servier.com under a Creative Commons Attribution 3.0 Unported License].

decrease in diastolic pressure accompanied with an increase in heart rate. The authors suggested a potential role for CGRP in modulating vascular tone in humans, and this was supported by findings from Girgis et al. (1985) demonstrating that CGRP concentration is fivefold higher than calcitonin. Given that it is widely expressed in the human body, these results raised 
the possibility that CGRP is a critical physiological regulator of vascular tone and hemodynamics.

Collectively, these studies laid the foundation for elucidating the biological actions of CGRP, which recently reached fruition in the field of migraine research where CGRP blockers are now used therapeutically (Edvinsson et al., 2018; Kee et al., 2018). Generally, the use of migraine blockers have not been associated with significant cardiovascular effects, indicating that CGRP does not play a major role in cardiovascular regulation in individuals with normal blood pressure (Bigal et al., 2015). Separately, there has been increasing research into elucidating the role of CGRP and of exogenous CGRP, in the cardiovascular system. However, the potential biological importance and underlying mechanisms, particularly with respect to heart failure, will be discussed in later sections.

\section{CALCITONIN GENE-RELATED PEPTIDE IN HYPERTENSION - VASCULAR-DEPENDENT EFFECTS}

Shekhar et al. (1991) was one of the first to demonstrate the cardiovascular effects of prolonged CGRP infusion $(8 \mathrm{ng} / \mathrm{kg} / \mathrm{min}$ for $8 \mathrm{~h}$ ) in $\mathrm{CHF}$ patients. In agreement with others, they reported significant decreases in cardiac and arterial pressures, as well as in pulmonary and systemic vascular resistance, and increases in cardiac output and stroke volume. Accordingly, the reported hemodynamic changes were absent 30 min after discontinuation of CGRP infusion, consistent with the short half-life of CGRP (approximately 7-30 min) (Kraenzlin et al., 1985).

Concomitantly, preclinical data from rodents have facilitated human studies. Research in the 1990s focusing on the role of CGRP in blood pressure control was dominated by preclinical hypertension studies carried out in rats that were spontaneously hypertensive (SHR), treated with hypertensive agents, or hypertensive due to surgical intervention. These studies and others reported in vivo evidence that CGRP can protect against hypertension and the vasoconstrictor effects of hypertensive agents including angiotensin-II (AngII) (Itabashi et al., 1988; Fujioka et al., 1991), noradrenaline (Fujioka et al., 1991), deoxycorticosterone-salt (Supowit et al., 1997; Supowit et al., 2005), and the nitric oxide synthase (NOS) inhibitor L-NAME (Gardiner et al., 1991; Gangula et al., 1997), making progress toward understanding the mechanism of action of CGRP (Kumar et al., 2019a). Kawasaki et al. (1990) found that reduced CGRP-containing nerves in SHRs contribute to the development and maintenance of hypertension, further supporting a protective role for CGRP in hypertension. Furthermore, ex vivo experiments, particularly in isolated arterial and mesenteric resistance vessels, have complemented the in vivo data to-date (Nelson et al., 1990; Kawasaki et al., 1998; Kawasaki et al., 1999).

It has been difficult to study $\alpha$-CGRP in vivo due to its peptide nature, therefore the use of genetically engineered mice has been fitting. Genetic deletion of CGRP has been reported to cause elevated baseline blood pressure in some (Gangula et al., 2000; Oh-hashi et al., 2001; Li et al., 2004; Mai et al., 2014) but not all studies (Smillie et al., 2014; Argunhan et al., 2021). This is likely due to differences in methodology, such as differences in the precise genetic deletion site when generating knockout (KO) mouse lines, particular strains preserving unique hemodynamic phenotypes, and the utilization of various different blood pressure measurement techniques. Most importantly, most preclinical hypertension studies conclude that genetic deletion of CGRP is detrimental, if not in a naïve state, then evidently in a stressed or hypertensive setting. This indicates that endogenous CGRP may only be functionally active in cardiovascular dysfunction. CGRP blockers (antibodies and now CGRP receptor antagonists) have been studied in humans with migraine over several years now (Al-Hassany and Van Den Brink, 2020). The majority of findings from recent clinical trials report little or no change in blood pressure from migraine patients who received anti-CGRP therapy. Additionally, very few cardiovascular sideeffects have been observed in migraine patients taking CGRP blockers (Tepper, 2019). Thus, it is not yet known whether CGRP has a functionally important cardiovascular role in humans, apart from the neurogenic vasodilator response observed typically in patients with migraine (Tepper, 2019). However, due to CGRP being widely expressed and the increasing evidence for a cardioprotective role, there are concerns regarding longterm blockade of CGRP in migraine patients who may also suffer from cardiovascular complications (Rubio-Beltran and Maassen van den Brink, 2019). The observation of cardiovascular adverse effects with CGRP blockers in migraine has not been commonly observed. However, a recent study conducted a retrospective analysis of cases reporting a CGRP receptor antagonist (erenumab) associated with elevated blood pressure (BP) (Saely et al., 2021). The authors identified 61 cases of elevated BP between May 2018 and April 2020, of which the median systolic BP increase was $39 \mathrm{~mm} \mathrm{Hg}$. Interestingly, $44 \%$ of reported cases required anti-hypertensive medication and the elevated BP occurred most frequently within a week of commencing erenumab treatment. Most importantly, the prescribing information for erenumab/Aimovig now includes hypertension. This further supports the need to continue monitoring cardiovascular parameters in those receiving antiCGRP therapy for migraine, in addition to continuing research within the CGRP and cardiovascular field (Saely et al., 2021).

Much like CGRP KO mice, RAMP1 KO mice develop high blood pressure (Tsujikawa et al., 2007) and knock-in or overexpression of human RAMP1 in all (Sabharwal et al., 2010) or solely neural tissues (Sabharwal et al., 2019) potentiates CGRP-dependent blood pressure reduction in AngII-induced hypertension. Additionally, in the periphery, in tissues such as skin, it is clear that CGRP is a potent vasodilator and is well placed to play a regulatory role, for example in the recovery of blood flow in the cold-induced vascular response (Aubdool et al., 2014), a response that diminishes as aging occurs (Thapa et al., 2021).

Our research group has reported that, despite a lack of vascular tone modulation at baseline, $\alpha$-CGRP-specific KO mice display elevated blood pressure after AngII or L-NAME treatment (Smillie et al., 2014; Argunhan et al., 2021). $\alpha$-CGRP KO mice present with hypertrophic vascular remodeling in their aortic tissues and increased mRNA levels of inflammatory and oxidative 
stress markers after 14 or 28 days of AngII treatment (Smillie et al., 2014). These results indicate a protective role for CGRP in AngII-induced pathophysiology, where the benefits are not limited to one system, but instead multiple processes in order to attenuate the pathophysiological changes induced by AngII.

Intriguingly, Smillie et al. (2014) also showed that AngIItreated $\alpha$-CGRP KO mice display a significant reduction in protein and mRNA expression of endothelial nitric oxide synthase (eNOS). These findings probed us to investigate whether $\alpha$-CGRP can protect against hypertension independently of eNOS in vivo. The decreased production of $\mathrm{NO}$ in pathological states disrupts the endothelial equilibrium thus leading to endothelial dysfunction. CGRP receptors are expressed in the plasma membrane of both endothelial and vascular smooth muscle cells, hence have the capacity to induce vasodilation via $\mathrm{NO}$-dependent and -independent pathways. However, there is very limited evidence of this in vivo. We demonstrated that $\alpha$-CGRP KO mice develop exacerbated hypertension and present with dysfunctional blood flow recovery in mesenteric vessels in vivo after chronic L-NAME administration (Argunhan et al., $2021)$ indicating that $\alpha$-CGRP can induce vasodilation and hence attenuate hypertension independently of NOS. These findings suggest that $\alpha$-CGRP may be able to offer protection to compensate for pathophysiological processes such as endothelial dysfunction, which contributes to hypertension and cardiovascular disease. We also found that 2 weeks of $\alpha$-CGRP infusion (165 ug/kg/day) via osmotic minipumps was able to reverse L-NAME-induced hypertension, left ventricular heart weight gain, and associated increases in mRNA expression of hypertrophic markers in $\alpha$-CGRP KO mice, providing evidence for the antihypertrophic effects of CGRP. Conversely, this means that the nitric oxide vasodilator pathway theoretically could compensate, in terms of vasodilation, when CGRP is inhibited.

Antihypertrophic effects of CGRP have also been investigated recently by Skaria et al. (2019). The authors examined whether endogenous, physical activity-induced $\alpha$-CGRP has blood pressure-independent cardioprotective effects in mice which had 1 kidney 1 clip ( $1 \mathrm{k} 1 \mathrm{c}$ ) surgery and hence developed chronic hypertension. The authors claimed that exercise has cardioprotective effects in chronic hypertension, which is mediated at least partially through endogenous $\alpha$-CGRP signaling. They demonstrated $\alpha$ CGRP concentration in plasma is significantly elevated after $7 \mathrm{~min}$ of running in hypertensive mice and showed that chronic exogenous CGRP infusion via osmotic minipumps can alleviate hypertension-induced hypertrophy and cardiac dysfunction by suppressing pathological cardiac growth and interstitial fibrosis. Importantly, CGRP was infused at a subpressor dose $(4 \mathrm{nM} / \mathrm{h})$, suggesting that CGRP administration can help to preserve cardiac function in chronic hypertension independent of its blood pressure lowering effect.

\section{LONG-LASTING AGONIST OF CALCITONIN GENE-RELATED PEPTIDE}

While the protective effects of CGRP discussed thus far are detailed and mostly consistent between research groups, they do not constitute a complete record of documented studies demonstrating a cardioprotective role of CGRP. It is apparent that the beneficial effects of CGRP have been limited due to its short peptide half-life. Our group was fortunate to investigate the therapeutic potential of a longer lasting CGRP agonist in AngIIinduced hypertension and mice that underwent abdominal aortic constriction surgery, which eventually caused heart failure via increased pressure-overload on the heart (Aubdool et al., 2017). The acylated $\alpha$-CGRP analog had been characterized by Nilsson et al. (2016) and has a half-life of $>7 \mathrm{~h}$ in rodents. Our group demonstrated that daily administration of the CGRP analog [50 nmol/ $\mathrm{kg} /$ day, subcutaneous injection (s.c.)] for 2 weeks in AngII-treated mice led to significant attenuation of AngII-induced hypertension and protected against vascular, renal and cardiac dysfunction. $\alpha$-CGRP analog-treated mice presented with attenuated hypertrophic and fibrotic markers as well as reduced inflammation and oxidative stress. Furthermore, the $\alpha$-CGRP analog was effective in preserving ejection fraction, a measure of cardiac function, and protecting against fibrosis and apoptosis in cardiac tissues of mice that had undergone abdominal aortic constriction surgery and consequently developed heart failure. Moreover, $\alpha$-CGRP-treated mice presented with better vascularization in their hearts and expressed reduced mRNA and protein expression of biomarkers for hypertrophy, apoptosis, oxidative stress and inflammation. These findings agree with other in vivo heart failure studies (Li et al., 2013; Kumar et al., 2019b; Kumar et al., 2020). In vitro experiments have demonstrated similar findings in different cell types. CGRP administration has been shown to: stimulate proliferation of endothelial cells (Haegerstrand et al., 1990), supporting CGRP's proangiogenic effects in vivo; reduce vascular smooth muscle cell proliferation ( $\mathrm{Li}$ et al., 1997) and thus vascular hypertrophy; and show antioxidant and antiapoptotic effects in dorsal root ganglion (DRG) neurons (Liu et al., 2019).

However, data from the Aubdool et al. (2017) study suggests these protective effects of CGRP can be long lasting using a novel $\alpha$-CGRP agonist with an extended half-life. The CGRP agonist can delay the onset and development of hypertension through cardioprotective mechanisms in addition to ameliorating pressure overload-induced heart failure. Interestingly, mice with heart failure that had received the $\alpha$-CGRP analog or its vehicle presented with comparable blood pressures, indicating that the cardioprotective mechanisms involved are likely to be blood pressure-independent. Furthermore, the same analog has recently been administered to rats that have undergone permanent occlusion of their left coronary artery to investigate coronary perfusion in myocardial infarction. Three injections of the CGRP analog, SAX, at $20 \mathrm{~min}, 24$ and $48 \mathrm{~h}$ after coronary ligation, was sufficient to improve myocardial perfusion recovery in rats, indicative of myocardium protection after ischemic damage (Bentsen et al., 2021). An earlier study by Kallner et al. (1998) reported CGRP-mediated improvement in post-ischemic coronary flow early after MI, but whether treatment with the long lasting agonist will increase cardioprotective effects in the long term is still to be investigated. 


\section{CALCITONIN GENE-RELATED PEPTIDE IN THE MYOCARDIUM - VASCULAR-INDEPENDENT EFFECTS}

The heart is densely innervated by nerve fibers comprised of: the sympathetic trunk, which starts from the base of the skull; parasympathetic nerves, including the right and left vagus nerves; cervical cardiac nerves, which run parallel to the vagus nerves; and the cardiac plexus at the base of the heart. $\alpha$-CGRP producing sensory nerves have been reported within the perivascular layer of coronary arteries, in the myocardium of ventricles, and within the cardiac conduction system (Gulbenkian et al., 1993). In addition to this, CGRP immunoreactivity has been associated with; myocytes from atria, coronary vessels, local parasympathetic ganglia and with epi-and endocardia (FrancoCereceda et al., 1987). Therefore, it is likely that CGRP signaling manifests within cardiac cells, in addition to cardiac vessels, and that the sensory, parasympathetic and sympathetic nerves are involved in facilitating CGRP-induced signaling within, and surrounding, the myocardium.

Several in vivo studies of hypertension and heart failure have reported an upregulation of RAMP1 and/or CGRP expression in pathological conditions (Supowit et al., 1995; Li and Wang, 2005; Aubdool et al., 2017; Argunhan et al., 2021). In addition to this, Franco-Cereceda and Liska (2000) have previously reported the presence of a subpopulation of capsaicin-sensitive cardiac C-fiber afferents that store CGRP, substance P and neurokinin A. The C-fibers are likely to express transient receptor potential vanilloid 1 (TRPV1) channel, which upon stimulation by capsaicin lead to CGRP release (Franco-Cereceda, 1991). This finding of local efferent release of CGRP in the heart is consistent with the presence of capsaicin-sensitive receptors on the epicardial surface of rat hearts (Zahner et al., 2003). More recently, Moreira et al. (2020) reported elevated CGRP levels in human atrial tissue lysates and atrial cardiomyocytes obtained from patients with atrial fibrillation, in agreement with Franco-Cereceda et al. (1987) who found between threefold and fourfold higher levels of CGRPlike immunoreactivity in atria compared to ventricles. These studies describe and support a structural basis for CGRP signaling within cardiac tissues.

Furthermore, coinciding with its interactions in vascular smooth muscle and endothelial cells, CGRP has similarly been demonstrated to bind to its canonical receptor complex and activate $\mathrm{G}_{\mathrm{s}}$-signaling in cardiomyocytes (Huang et al., 1999; Sueur et al., 2005; Schavinski et al., 2021). It is well established that an increase in cAMP concentration followed by PKA activation leads to phosphorylation of key $\mathrm{Ca}^{2+}$. handling proteins including phospholamban, ryanodine receptor, voltage-gated L-type $\mathrm{Ca}^{2+}$ channels, troponin I, and myosin binding protein $\mathrm{C}$; all which play an essential role in cardiac excitability and contraction (Zaccolo, 2009). Earlier studies have reported that activation of the CRLR/RAMP1 complex leads to stimulation of a contractile response in adult rat ventricular cardiomyocytes (Bell and McDermott, 1994; Bell et al., 1995). However, unlike the vascular-dependent effects of CGRP, the precise mechanism of action of CGRP in cardiomyocytes remains to be fully elucidated.
Interestingly, a recent study investigating GPCR agonist bias in CGRP and CGRP-like family peptides demonstrated that, in human ventricular cardiomyocytes, CGRP is more potent than adrenomedullin and adrenomedullin 2/intermedin in generating cAMP (Clark et al., 2021). Acute cAMP elevation is known to compensate for impaired cardiac function by modulating the positive-inotropic, -chronotropic and -lusitropic responses in the heart. Thus, in addition to its vascular dependent actions, it is tempting to speculate that CGRP-induced positive-inotropy and -chronotropy observed in earlier human studies could be a consequence of vascular-independent actions via direct interaction with cardiomyocytes. Chronic cAMP activation, however, has been associated with adverse cardiac remodeling (Triposkiadis et al., 2009). Importantly, cAMP is a pleiotropic secondary messenger and thus able to produce several biological outcomes in response to different stimuli. Moreover, locally accumulated cAMP has been shown to ameliorate cardiac hypertrophy via cAMP-degrading enzyme phosphodiesterase2 (PDE2; Zoccarato et al., 2015). The regulation and function of local cAMP-PKA signaling remains to be fully understood, and compartmentalized cAMP-PKA has been suggested to play a key role in cardiac physiology and pathophysiology (Surdo et al., 2017).

Coupling of the CRLR-RAMP1 complex to $G \alpha_{s}$ can lead to other responses such as phosphorylation of ERK1/2 or cell proliferation; a response which has been suggested to be cell type dependent (Clark et al., 2021). Interestingly, the CGRP family of receptors, including CRLR/RAMP1, can couple to $\mathrm{G} \alpha_{i}$ and $\mathrm{G} \alpha_{\mathrm{q}}$ subunits too, although there is little evidence of this in cardiomyocytes (Nishikimi et al., 1998; Walker et al., 2010). These findings further support the need to investigate CGRP-signaling in cardiomyocytes and fibroblasts in vitro, which may help to clarify the mechanism of action behind the cardioprotective effects of CGRP reported in whole body physiology studies (Li et al., 2013; Aubdool et al., 2017; Kumar et al., 2019b; Skaria et al., 2019; Kumar et al., 2020; Argunhan et al., 2021), especially in studies that have shown blood pressure independent effects of CGRP (Aubdool et al., 2017; Skaria et al., 2019).

In addition to its direct effect on cardiomyocytes, CGRP has also been shown to modulate sympathetic nervous activity (Figure 1B). Activation of $\beta$-adrenoceptors via increased sympathetic nervous activity leads to $G \alpha_{s}$-signaling-induced cardiac contractility. Earlier studies suggest that CGRP-induced positive inotropic effects may be, at least partially, due to increased sympathetic activity (Fisher et al., 1983; Gennari and Fischer, 1985; Struthers et al., 1986; Katori et al., 2005). On the other hand, Kawasaki (2002) reported that exogenous CGRP treatment can impair noradrenergic-induced constriction in rat mesenteric vessels. Thus, it is thought the activation or increased sympathetic activity reported in some studies is part of a compensatory reflex system to combat CGRP-induced hypotension. Considering that exogenous administration of CGRP primarily lowers blood pressure, its ability to stimulate the sympathetic nervous system is likely to be minimal and secondary to its primary action of inducing vasodilation. Evidence suggests that stimulation of the sympathetic nervous system may be one of the mechanisms CGRP is able to stimulate in situations where inotropic support is necessary (Figure 1B). 
It is unclear whether the aforementioned inotropic effects of CGRP are solely a consequence CGRP directly binding to its receptor complex found on myocardial cells (Bell and McDermott, 1994), modulation of the sympathetic nervous system, or an as yet unknown mechanism. A combination of these pathways is likely, with the choice dependent on the pathophysiological setting. It is important to acknowledge that selective and non-selective $\beta$-blockers, which target $\beta$-adrenoreceptors, constitute well-established therapeutics for cardiovascular diseases such as hypertension, coronary artery disease and severe tachycardia. They decrease contractility, thus reducing cardiac output and oxygen demand (Chatterjee et al., 2013; McDonagh et al., 2021), and are therefore part of the evidence-based long-term management of heart failure with reduced ejection fraction (HFrEF). $\beta$-blockers are, however, concurrently used with ACE inhibitors, and in many cases, an aldosterone inhibitor or diuretic, to off-set other symptoms of heart failure. Despite being generally well tolerated and recommended as pharmacological therapeutics for heart failure patients who require long-term management of their medical symptoms, there remains an unmet therapeutic need for better management of HF pathophysiology.

Contrary to the above, increasing inotropy can also be of benefit in heart failure patients (Page et al., 2016). However, this is specifically for those who require inotropic- or shortterm hemodynamic support due to suffering with decompensated HFrEF, presenting with low cardiac output and hypotension or evidence of end-organ hypoperfusion (McDonagh et al., 2021). Sympathetic cardiac stimulants such as dopamine and dobutamine are therefore still recommended for use in such cases (Bistola et al., 2019) and vasodilator therapeutics are also first-line agents for acute HF with elevated blood pressure (McDonagh et al., 2021). Human studies suggest that CGRP administration is protective in patients who require shortterm inotropic support, whilst long-term pre-clinical studies indicate CGRP can improve cardiovascular function parameters in pressure-overload-induced heart failure.

However, whether a sub-pressor dose of CGRP can protect against the development and progression of hypertension and heart failure needs to be investigated further. If CGRP can indeed protect against cardiovascular disease without lowering blood pressure, this answers one query but raises further questions regarding its mechanism of action. Vasodilators are known to primarily reduce total peripheral resistance via vasodilation in blood vessels, thus lowering blood pressure. This in turn acutely enhances sympathetic stimulation due to the baroreceptor reflex, hence increasing heart rate and cardiac contractility (positivechronotropy and -inotropy) in the short-term. The dilation of venous and arterial vessels also leads to a reduction in venous return to the heart (pre-load), which reduces congestion and after-load, therefore increasing stroke volume, cardiac output and subsequent relief of symptoms. It is for these reasons that vasodilators such as nitrates or nitroprusside are recommended for management of acute heart failure (AHF) in patients with elevated blood pressure (McDonagh et al., 2021). If a dilator such as CGRP does not affect blood pressure but is able to improve cardiac function, this adds complexity to our understanding of how vasodilators can modulate cardiac function. The recent data from Aubdool et al. (2017) and Skaria et al. (2019) suggests that CGRP can regulate cardiac function independently of blood pressure, thus via vascular-dependent and -independent pathways.

Collectively, these studies propose vascular-independent mechanisms for CGRP in cardiac tissues and may be the primary mechanism by which CGRP elicits protection in the absence of vascular tone changes. There is evidence supporting that CGRP can act locally on cardiomyocytes to elicit some of its cardioprotective actions, and future studies should aim to clarify the precise mechanism(s) involved in cardiac pathophysiology.

\section{DISCUSSION}

A wide spectrum of in vitro, ex vivo, in vivo and human studies have highlighted the therapeutic potential of CGRP in various pathophysiological conditions within the cardiovascular system. Genetic tools such as transgenic mouse lines combined with pharmacological agents including CGRP peptide administration systems and delivery of selective receptor antagonists, means that researchers are well-equipped to investigate the effects of reduced, enhanced and lack of CGRP signaling in whole body pathophysiology studies. More recently, anti-CGRP therapies for treatment of migraine have proven to be successful with generally minimal adverse effects reported. Additional follow-up clinical trials will be welcomed by all to clarify whether long-term CGRP blockade leads to hypertension-related side effects. Meanwhile, long lasting agonists have emerged as a promising avenue for CGRPtherapy in cardiovascular disease, which will facilitate research into the intrinsic proliferative and angiogenic characteristics of CGRP, in addition to its anti-inflammatory and antiapoptotic effects reported in vivo. Future studies should aim to investigate the blood pressure-independent cardioprotective mechanisms of CGRP treatment in PO-induced heart failure, and whether treatment with the long-lasting agonist could improve outcome after ischemic heart failure. Collectively, these findings further demonstrate the importance of continuing CGRP research to fully elucidate the physiological influence of CGRP in the cardiovascular system, as well as in migraine pathophysiology.

\section{AUTHOR CONTRIBUTIONS}

FA wrote the first draft. Both FA and SDB finalised the manuscript. Both authors contributed to the article and approved the submitted version.

\section{FUNDING}

This work was funded by the British Heart Foundation PG/19/14/34268. We apologize to our colleagues whose work could not be cited due to space restraints. 


\section{REFERENCES}

Al-Hassany, L., and Van Den Brink, A. M. (2020). Targeting CGRP in migraine: a matter of choice and dose. Lancet Neurol. 19, 712-713. doi: 10.1016/S14744422(20)30282-9

Amara, S. G., Arriza, J. L., Leff, S. E., Swanson, L. W., Evans, R. M., and Rosenfeld, M. G. (1985). Expression in brain of a messenger RNA encoding a novel neuropeptide homologous to calcitonin gene-related peptide. Science 229, 1094-1097. doi: 10.1126/science. 2994212

Amara, S. G., Jonas, V., Rosenfeld, M. G., Ong, E. S., and Evans, R. M. (1982). Alternative RNA processing in calcitonin gene expression generates mRNAs encoding different polypeptide products. Nature 298, 240-244. doi: 10.1038/ $298240 \mathrm{a} 0$

Argunhan, F., Thapa, D., Aubdool, A. A., Carlini, E., Arkless, K., Hendrikse, E. R., et al. (2021). Calcitonin gene-related peptide protects against cardiovascular dysfunction independently of nitric oxide In Vivo. Hypertension 77, 1178-1190. doi: 10.1161/HYPERTENSIONAHA.120.14851

Aubdool, A. A., Graepel, R., Kodji, X., Alawi, K. M., Bodkin, J. V., Srivastava, S., et al. (2014). TRPA1 is essential for the vascular response to environmental cold exposure. Nat. Commun. 5:5732. doi: 10.1038/ncomms6732

Aubdool, A. A., Thakore, P., Argunhan, F., Smillie, S. J., Schnelle, M., Srivastava, S., et al. (2017). A novel alpha-calcitonin gene-related peptide analogue protects against end-organ damage in experimental hypertension, cardiac hypertrophy, and heart failure. Circulation 136, 367-383. doi: 10.1161/circulationaha.117. 028388

Bell, D., and McDermott, B. J. (1994). Calcitonin gene-related peptide stimulates a positive contractile response in rat ventricular cardiomyocytes. J. Cardiovasc. Pharmacol. 23, 1011-1021. doi: 10.1097/00005344-199406000-00021

Bell, D., Schluter, K. D., Zhou, X. J., Mcdermott, B. J., and Piper, H. M. (1995). Hypertrophic effects of calcitonin gene-related peptide (Cgrp) and amylin on adult mammalian ventricular cardiomyocytes. J. Mol. Cell Cardiol. 27, 2433-2443. doi: 10.1006/jmcc.1995.0231

Bentsen, S., Sams, A., Hasbak, P., Edvinsson, L., Kjaer, A., and Ripa, R. S. (2021). Myocardial perfusion recovery induced by an alpha-calcitonin gene-related peptide analogue. J. Nucl. Cardiol. (in press). doi: 10.1007/s12350-021-02678-8

Bigal, M. E., Walter, S., and Rapoport, A. M. (2015). Therapeutic antibodies against CGRP or its receptor. Br. J. Clin. Pharmacol. 79, 886-895.

Bistola, V., Arfaras-Melainis, A., Polyzogopoulou, E., Ikonomidis, I., and Parissis, J. (2019). Inotropes in acute heart failure: from guidelines to practical use: therapeutic options and clinical practice. Card. Fail. Rev. 5, 133-139. doi: 10. 15420/cfr.2019.11.2

Brain, S. D., and Grant, A. D. (2004). Vascular actions of calcitonin gene-related peptide and adrenomedullin. Physiol. Rev. 84, 903-934. doi: 10.1152/physrev. 00037.2003

Brain, S. D., Tippins, J. R., Morris, H. R., Macintyre, I., and Williams, T. J. (1986). Potent vasodilator activity of calcitonin gene-related peptide in human skin. J. Invest. Dermatol. 87, 533-536. doi: 10.1111/1523-1747.ep12455620

Brain, S. D., Williams, T. J., Tippins, J. R., Morris, H. R., and Macintyre, I. (1985). Calcitonin gene-related peptide is a potent vasodilator. Nature 313, 54-56.

Chatterjee, S., Biondi-Zoccai, G., Abbate, A., D'ascenzo, F., Castagno, D., Van Tassell, B., et al. (2013). Benefits of beta blockers in patients with heart failure and reduced ejection fraction: network meta-analysis. BMJ 346:f55. doi: 10 . 1136/bmj.f55

Clark, A. J., Mullooly, N., Safitri, D., Harris, M., De Vries, T., Maassenvandenbrink, A., et al. (2021). CGRP, adrenomedullin and adrenomedullin 2 display endogenous Gpcr agonist bias in primary human cardiovascular cells. Commun. Biol. 4:776. doi: 10.1038/s42003-021-02293-w

Crossman, D. C., Dashwood, M. R., Brain, S. D., Mcewan, J., and Pearson, J. D. (1990). Action of calcitonin gene-related peptide upon bovine vascular endothelial and smooth muscle cells grown in isolation and co-culture. $\mathrm{Br}$. J. Pharmacol. 99, 71-76. doi: 10.1111/j.1476-5381.1990.tb14656.x

Edvinsson, L., Haanes, K. A., Warfvinge, K., and Krause, D. N. (2018). CGRP as the target of new migraine therapies - successful translation from bench to clinic. Nat. Rev. Neurol. 14, 338-350. doi: 10.1038/s41582-018-0003-1

Fisher, L. A., Kikkawa, D. O., Rivier, J. E., Amara, S. G., Evans, R. M., Rosenfeld, M. G., et al. (1983). Stimulation of noradrenergic sympathetic outflow by calcitonin gene-related peptide. Nature 305, 534-536. doi: 10.1038/305534a0
Franco-Cereceda, A. (1991). Calcitonin gene-related peptide and human epicardial coronary arteries: presence, release and vasodilator effects. Br. J. Pharmacol. 102, 506-510. doi: 10.1111/j.1476-5381.1991.tb12201.x

Franco-Cereceda, A., and Liska, J. (2000). Potential of calcitonin gene-related peptide in coronary heart disease. Pharmacology 60, 1-8. doi: 10.1159/ 000028339

Franco-Cereceda, A., Henke, H., Lundberg, J. M., Petermann, J. B., Hokfelt, T., and Fischer, J. A. (1987). Calcitonin gene-related peptide (CGRP) in capsaicinsensitive substance P-immunoreactive sensory neurons in animals and man: distribution and release by capsaicin. Peptides 8, 399-410. doi: 10.1016/01969781(87)90117-3

Fujioka, S., Sasakawa, O., Kishimoto, H., Tsumura, K., and Morii, H. (1991). The antihypertensive effect of calcitonin gene-related peptide in rats with norepinephrine- and angiotensin II-induced hypertension. J. Hypertens. 9, 175-179. doi: 10.1097/00004872-199102000-00013

Gangula, P. R., Supowit, S. C., Wimalawansa, S. J., Zhao, H., Hallman, D. M., Dipette, D. J., et al. (1997). Calcitonin gene-related peptide is a depressor in NG-nitro-L-arginine methyl ester-induced hypertension during pregnancy. Hypertension 29, 248-253. doi: 10.1161/01.hyp.29.1.248

Gangula, P. R., Zhao, H., Supowit, S. C., Wimalawansa, S. J., Dipette, D. J., Westlund, K. N., et al. (2000). Increased blood pressure in alpha-calcitonin gene-related peptide/calcitonin gene knockout mice. Hypertension 35, 470-475. doi: 10.1161/01.hyp.35.1.470

Gardiner, S. M., Compton, A. M., Kemp, P. A., Bennett, T., Foulkes, R., and Hughes, B. (1991). Haemodynamic effects of human alpha-calcitonin gene-related peptide following administration of endothelin-1 or NG-nitroL-arginine methyl ester in conscious rats. Br. J. Pharmacol. 103, 1256-1262. doi: 10.1111/j.1476-5381.1991.tb12333.x

Gennari, C., and Fischer, J. A. (1985). Cardiovascular action of calcitonin generelated peptide in humans. Calcif. Tissue Int. 37, 581-584. doi: 10.1007/ BF02554909

Gennari, C., Nami, R., Agnusdei, D., and Fischer, J. A. (1990). Improved cardiac performance with human calcitonin gene related peptide in patients with congestive heart failure. Cardiovasc. Res. 24, 239-241. doi: 10.1093/cvr/24.3.239

Gibson, S. J., Polak, J. M., Bloom, S. R., Sabate, I. M., Mulderry, P. M., Ghatei, M. A., et al. (1984). Calcitonin gene-related peptide immunoreactivity in the spinal cord of man and of eight other species. J. Neurosci. 4, 3101-3111. doi: 10.1523/JNEUROSCI.04-12-03101.1984

Girgis, S. I., Macdonald, D. W., Stevenson, J. C., Bevis, P. J., Lynch, C., Wimalawansa, S. J., et al. (1985). Calcitonin gene-related peptide: potent vasodilator and major product of calcitonin gene. Lancet 2, 14-16. doi: 10.1016/ s0140-6736(85)90059-5

Gray, D. W., and Marshall, I. (1992a). Human alpha-calcitonin gene-related peptide stimulates adenylate cyclase and guanylate cyclase and relaxes rat thoracic aorta by releasing nitric oxide. Br. J. Pharmacol. 107, 691-696. doi: 10.1111/j.1476-5381.1992.tb14508.x

Gray, D. W., and Marshall, I. (1992b). Nitric oxide synthesis inhibitors attenuate calcitonin gene-related peptide endothelium-dependent vasorelaxation in rat aorta. Eur. J. Pharmacol. 212, 37-42. doi: 10.1016/0014-2999(92)90069-g

Gulbenkian, S., Saetrum Opgaard, O., Ekman, R., Costa Andrade, N., Wharton, J., Polak, J. M., et al. (1993). Peptidergic innervation of human epicardial coronary arteries. Circ. Res. 73, 579-588. doi: 10.1161/01.res.73.3.579

Haegerstrand, A., Dalsgaard, C. J., Jonzon, B., Larsson, O., and Nilsson, J. (1990). Calcitonin gene-related peptide stimulates proliferation of human endothelial cells. Proc. Natl. Acad. Sci. U.S.A. 87, 3299-3303. doi: 10.1073/pnas.87.9. 3299

Hay, D. L., Garelja, M. L., Poyner, D. R., and Walker, C. S. (2018). Update on the pharmacology of calcitonin/Cgrp family of peptides: iuphar review 25. Br. J. Pharmacol. 175, 3-17. doi: 10.1111/bph.14075

Huang, M. H., Knight, P. R. III, and Izzo, J. L. Jr. (1999). Ca2+-induced Ca2+ release involved in positive inotropic effect mediated by Cgrp in ventricular myocytes. Am. J. Physiol. 276, R259-R264. doi: 10.1152/ajpregu.1999.276.1. R259

Itabashi, A., Kashiwabara, H., Shibuya, M., Tanaka, K., Masaoka, H., Katayama, S., et al. (1988). The interaction of calcitonin gene-related peptide with angiotensin Ii on blood pressure and renin release. J. Hypertens. Suppl. 6, S418-S420. doi: 10.1097/00004872-198812040-00131 
Josephs, T. M., Belousoff, M. J., Liang, Y. L., Piper, S. J., Cao, J., Garama, D. J., et al. (2021). Structure and dynamics of the Cgrp receptor in apo and peptide-bound forms. Science 372:eabf7258. doi: 10.1126/science.abf7258

Kallner, G., Gonon, A., and Franco-Cereceda, A. (1998). Calcitonin gene-related peptide in myocardial ischaemia and reperfusion in the pig. Cardiovasc. Res. 38, 493-499. doi: 10.1016/s0008-6363(98)00016-9

Katori, T., Hoover, D. B., Ardell, J. L., Helm, R. H., Belardi, D. F., Tocchetti, C. G., et al. (2005). Calcitonin gene-related peptide in vivo positive inotropy is attributable to regional sympatho-stimulation and is blunted in congestive heart failure. Circ. Res. 96, 234-243. doi: 10.1161/01.RES.0000152969.42117.ca

Kawasaki H. (2002). Regulation of vascular function by perivascular calcitonin gene-related peptide-containing nerves. Jpn. J. Pharmacol. 88, 39-43. doi: 10. 1254/JP.88.39

Kawasaki, H., Okazaki, M., Nakatsuma, A., Mimaki, Y., Araki, H., and Gomita, Y. (1999). Long-term treatment with angiotensin converting enzyme inhibitor restores reduced calcitonin gene-related peptide-containing vasodilator nerve function in mesenteric artery of spontaneously hypertensive rats. Jpn. J. Pharmacol. 79, 221-229. doi: 10.1254/jjp.79.221

Kawasaki, H., Saito, A., and Takasaki, K. (1990). Age-related decrease of calcitonin gene-related peptide-containing vasodilator innervation in the mesenteric resistance vessel of the spontaneously hypertensive rat. Circ. Res. 67, 733-743. doi: 10.1161/01.res.67.3.733

Kawasaki, H., Takenaga, M., Araki, H., Futagami, K., and Gomita, Y. (1998). Angiotensin inhibits neurotransmission of calcitonin gene-related peptide-containing vasodilator nerves in mesenteric artery of spontaneously hypertensive rats. J. Pharmacol. Exp. Ther. 284, 508-515.

Kee, Z., Kodji, X., and Brain, S. D. (2018). The role of calcitonin gene related peptide (CGRP) in neurogenic vasodilation and its cardioprotective effects. Front. Physiol. 9:1249. doi: 10.3389/fphys.2018.01249

Kraenzlin, M. E., Ch'ng, J. L., Mulderry, P. K., Ghatei, M. A., and Bloom, S. R. (1985). Infusion of a novel peptide, calcitonin gene-related peptide (CGRP) in man. Pharmacokinetics and effects on gastric acid secretion and on gastrointestinal hormones. Regul. Pept. 10, 189-197. doi: 10.1016/01670115(85)90013-8

Kumar, A., Belhaj, M., Dipette, D. J., and Potts, J. D. (2020). A novel alginate-based delivery system for the prevention and treatment of pressure-overload induced heart failure. Front. Pharmacol. 11:602952. doi: 10.3389/fphar.2020.602952

Kumar, A., Potts, J. D., and Dipette, D. J. (2019a). Protective role of alpha-calcitonin gene-related peptide in cardiovascular diseases. Front. Physiol. 10:821. doi: 10. 3389/fphys.2019.00821

Kumar, A., Supowit, S., Potts, J. D., and Dipette, D. J. (2019b). Alpha-calcitonin gene-related peptide prevents pressure-overload induced heart failure: role of apoptosis and oxidative stress. Physiol. Rep. 7:e14269. doi: 10.14814/phy2.14269

Li, J., and Wang, D. H. (2005). Development of angiotensin II-induced hypertension: role of CGRP and its receptor. J. Hypertens. 23, 113-118. doi: 10.1097/00004872-200501000-00020

Li, J., Levick, S. P., Dipette, D. J., Janicki, J. S., and Supowit, S. C. (2013). Alphacalcitonin gene-related peptide is protective against pressure overload-induced heart failure. Regul. Pept. 185, 20-28. doi: 10.1016/j.regpep.2013.06.008

Li, J., Zhao, H., Supowit, S. C., Dipette, D. J., and Wang, D. H. (2004). Activation of the renin-angiotensin system in alpha-calcitonin gene-related peptide/calcitonin gene knockout mice. J. Hypertens. 22, 1345-1349. doi: 10. 1097/01.hjh.0000125409.50839.f1

Li, Y., Fiscus, R. R., Wu, J., Yang, L., and Wang, X. (1997). The antiproliferative effects of calcitonin gene-related peptide in different passages of cultured vascular smooth muscle cells. Neuropeptides 31, 503-509. doi: 10.1016/s01434179(97)90046-9

Liang, Y. L., Khoshouei, M., Deganutti, G., Glukhova, A., Koole, C., Peat, T. S., et al. (2018). Cryo-EM structure of the active, Gs-protein complexed, human Cgrp receptor. Nature 561, 492-497. doi: 10.1038/s41586-018-0535-y

Liu, Y., Zhang, S., Xue, J., Wei, Z., Ao, P., Shen, B., et al. (2019). Cgrp reduces apoptosis of DRG cells induced by high-glucose oxidative stress injury through PI3K/AKT induction of heme oxygenase-1 and Nrf-2 expression. Oxid. Med. Cell Longev. 2019:2053149. doi: 10.1155/2019/2053149

Mai, T. H., Wu, J., Diedrich, A., Garland, E. M., and Robertson, D. (2014). Calcitonin gene-related peptide (CGRP) in autonomic cardiovascular regulation and vascular structure. J. Am. Soc. Hypertens. 8, 286-296. doi: 10. 1016/j.jash.2014.03.001
McDonagh, T. A., Metra, M., Adamo, M., Gardner, R. S., Baumbach, A., Bohm, M., et al. (2021). 2021 ESC guidelines for the diagnosis and treatment of acute and chronic heart failure. Eur. Heart J. 42, 3599-3726.

McLatchie, L. M., Fraser, N. J., Main, M. J., Wise, A., Brown, J., Thompson, N., et al. (1998). RAMPS regulate the transport and ligand specificity of the calcitonin-receptor-like receptor. Nature 393, 333-339. doi: 10.1038/30666

Moreira, L. M., Takawale, A., Hulsurkar, M., Menassa, D. A., Antanaviciute, A., Lahiri, S. K., et al. (2020). Paracrine signalling by cardiac calcitonin controls atrial fibrogenesis and arrhythmia. Nature 587, 460-465. doi: 10.1038/s41586020-2890-8

Nelson, M. T., Huang, Y., Brayden, J. E., Hescheler, J., and Standen, N. B. (1990). Arterial dilations in response to calcitonin gene-related peptide involve activation of K+ channels. Nature 344, 770-773. doi: 10.1038/344770a0

Nilsson, C., Hansen, T. K., Rosenquist, C., Hartmann, B., Kodra, J. T., Lau, J. F., et al. (2016). Long acting analogue of the calcitonin gene-related peptide induces positive metabolic effects and secretion of the glucagon-like peptide- 1 . Eur. J. Pharmacol. 773, 24-31. doi: 10.1016/j.ejphar.2016.01.003

Nishikimi, T., Horio, T., Yoshihara, F., Nagaya, N., Matsuo, H., and Kangawa, K. (1998). Effect of adrenomedullin on cAMP and cGMP levels in rat cardiac myocytes and nonmyocytes. Eur. J. Pharmacol. 353, 337-344. doi: 10.1016/ s0014-2999(98)00400-2

Oh-hashi, Y., Shindo, T., Kurihara, Y., Imai, T., Wang, Y., Morita, H., et al. (2001). Elevated sympathetic nervous activity in mice deficient in alphacgrp. Circ. Res. 89, 983-990. doi: 10.1161/hh2301.100812

Page, R. L. II, O’bryant, C. L., Cheng, D., Dow, T. J., Ky, B., Stein, C. M., et al. (2016). Drugs that may cause or exacerbate heart failure: a scientific statement from the american heart association. Circulation 134, e32-e69.

Pioszak, A. A., and Hay, D. L. (2020). RAMPs as allosteric modulators of the calcitonin and calcitonin-like class B G protein-coupled receptors. $A d v$. Pharmacol. 88, 115-141. doi: 10.1016/bs.apha.2020.01.001

Rubio-Beltran, E., and Maassen van den Brink, A. (2019). Understanding CGRP and cardiovascular risk. Handb. Exp. Pharmacol. 255, 131-140. doi: 10.1007/ 164_2019_204

Russell, F. A., King, R., Smillie, S. J., Kodji, X., and Brain, S. D. (2014). Calcitonin gene-related peptide: physiology and pathophysiology. Physiol. Rev. 94, 10991142. doi: 10.1152/physrev.00034.2013

Sabharwal, R., Mason, B. N., Kuburas, A., Abboud, F. M., Russo, A. F., and Chapleau, M. W. (2019). Increased receptor activity-modifying protein 1 in the nervous system is sufficient to protect against autonomic dysregulation and hypertension. J. Cereb. Blood Flow Metab. 39, 690-703. doi: 10.1177/ $0271678 X 17751352$

Sabharwal, R., Zhang, Z., Lu, Y., Abboud, F. M., Russo, A. F., and Chapleau, M. W. (2010). Receptor activity-modifying protein 1 increases baroreflex sensitivity and attenuates Angiotensin-induced hypertension. Hypertension 55, 627-635. doi: 10.1161/HYPERTENSIONAHA.109.148171

Saely, S., Croteau, D., Jawidzik, L., Brinker, A., and Kortepeter, C. (2021). Hypertension: A new safety risk for patients treated with erenumab. Headache 61, 202-208. doi: 10.1111/head.14051

Schavinski, A. Z., Machado, J., Morgan, H. J. N., Lautherbach, N., Paula-Gomes, S., Kettelhut, I. C., et al. (2021). Calcitonin gene-related peptide exerts inhibitory effects on autophagy in the heart of mice. Peptides 146:170677. doi: 10.1016/j. peptides.2021.170677

Shekhar, Y. C., Anand, I. S., Sarma, R., Ferrari, R., Wahi, P. L., and PooleWilson, P. A. (1991). Effects of prolonged infusion of human alpha calcitonin gene-related peptide on hemodynamics, renal blood flow and hormone levels in congestive heart failure. Am. J. Cardiol. 67, 732-736. doi: 10.1016/00029149(91)90531-o

Skaria, T., Mitchell, K. J., Vogel, O., Walchli, T., Gassmann, M., and Vogel, J. (2019). Blood pressure normalization-independent cardioprotective effects of endogenous, physical activity-induced alphaCGRP (alpha calcitonin gene-related peptide) in chronically hypertensive mice. Circ. Res. 125, 1124-1140. doi: 10.1161/CIRCRESAHA.119.31 5429

Smillie, S. J., King, R., Kodji, X., Outzen, E., Pozsgai, G., Fernandes, E., et al. (2014). An ongoing role of alpha-calcitonin gene-related peptide as part of a protective network against hypertension, vascular hypertrophy, and oxidative stress. Hypertension 63, 1056-1062. doi: 10.1161/HYPERTENSIONAHA.113. 02517 
Steenbergh, P. H., Hoppener, J. W., Zandberg, J., Lips, C. J., and Jansz, H. S. (1985). A second human calcitonin/CGRP gene. FEBS Lett. 183, 403-407.

Struthers, A. D., Brown, M. J., Macdonald, D. W., Beacham, J. L., Stevenson, J. C., Morris, H. R., et al. (1986). Human calcitonin gene related peptide: a potent endogenous vasodilator in man. Clin. Sci. (Lond) 70, 389-393. doi: 10.1042/ cs0700389

Sueur, S., Pesant, M., Rochette, L., and Connat, J. L. (2005). Antiapoptotic effect of calcitonin gene-related peptide on oxidative stress-induced injury in $\mathrm{H} 9 \mathrm{c} 2$ cardiomyocytes via the Ramp1/Crlr complex. J. Mol. Cell Cardiol. 39, 955-963. doi: 10.1016/j.yjmcc.2005.09.008

Supowit, S. C., Rao, A., Bowers, M. C., Zhao, H., Fink, G., Steficek, B., et al. (2005). Calcitonin gene-related peptide protects against hypertension-induced heart and kidney damage. Hypertension 45, 109-114. doi: 10.1161/01.HYP. 0000151130.34874.fa

Supowit, S. C., Zhao, H., Hallman, D. M., and Dipette, D. J. (1997). Calcitonin gene-related peptide is a depressor of deoxycorticosterone-salt hypertension in the rat. Hypertension 29, 945-950. doi: 10.1161/01.hyp.29.4.945

Supowit, S. C., Zhao, H., Wang, D. H., and Dipette, D. J. (1995). Regulation of neuronal calcitonin gene-related peptide expression. Role of increased blood pressure. Hypertension 26, 1177-1180. doi: 10.1161/01.hyp.26.6. 1177

Surdo, N. C., Berrera, M., Koschinski, A., Brescia, M., Machado, M. R., Carr, C., et al. (2017). FRET biosensor uncovers camp nano-domains at beta-adrenergic targets that dictate precise tuning of cardiac contractility. Nat. Commun. 8:15031. doi: $10.1038 /$ ncomms15031

Tepper, S. J. (2019). Cgrp and headache: a brief review. Neurol. Sci. 40, 99-105. doi: 10.1007/s10072-019-03769-8

Thapa, D., Valente, J. S., Barrett, B., Smith, M. J., Argunhan, F., Lee, S. Y., et al. (2021). Dysfunctional Trpm8 signalling in the vascular response to environmental cold in ageing. eLife 10:e70153. doi: 10.7554/eLife.7 0153

Triposkiadis, F., Karayannis, G., Giamouzis, G., Skoularigis, J., Louridas, G., and Butler, J. (2009). The sympathetic nervous system in heart failure physiology, pathophysiology, and clinical implications. J. Am. Coll. Cardiol. 54, 1747-1762. doi: 10.1016/j.jacc.2009.05.015

Tsujikawa, K., Yayama, K., Hayashi, T., Matsushita, H., Yamaguchi, T., Shigeno, T., et al. (2007). Hypertension and dysregulated proinflammatory cytokine production in receptor activity-modifying protein 1-deficient mice. Proc. Natl. Acad. Sci. U.S.A. 104, 16702-16707. doi: 10.1073/pnas.0705974104

Walker, C. S., Conner, A. C., Poyner, D. R., and Hay, D. L. (2010). Regulation of signal transduction by calcitonin gene-related peptide receptors. Trends Pharmacol. Sci. 31, 476-483. doi: 10.1016/j.tips.2010.06.006

Weston, C., Winfield, I., Harris, M., Hodgson, R., Shah, A., Dowell, S. J., et al. (2016). Receptor activity-modifying protein-directed G protein signaling specificity for the calcitonin gene-related peptide family of receptors. J. Biol. Chem. 291, 21925-21944.

Zaccolo, M. (2009). cAMP signal transduction in the heart: understanding spatial control for the development of novel therapeutic strategies. Br. J. Pharmacol. 158, 50-60. doi: 10.1111/j.1476-5381.2009.00185.x

Zahner, M. R., Li, D. P., Chen, S. R., and Pan, H. L. (2003). Cardiac vanilloid receptor 1-expressing afferent nerves and their role in the cardiogenic sympathetic reflex in rats. J. Physiol. 551, 515-523. doi: 10.1113/jphysiol.2003. 048207

Zoccarato, A., Surdo, N. C., Aronsen, J. M., Fields, L. A., Mancuso, L., Dodoni, G., et al. (2015). Cardiac hypertrophy is inhibited by a local pool of cAMP regulated by phosphodiesterase 2. Circ. Res. 117, 707-719. doi: 10.1161/CIRCRESAHA. 114.305892

Conflict of Interest: The authors declare that the research was conducted in the absence of any commercial or financial relationships that could be construed as a potential conflict of interest.

Publisher's Note: All claims expressed in this article are solely those of the authors and do not necessarily represent those of their affiliated organizations, or those of the publisher, the editors and the reviewers. Any product that may be evaluated in this article, or claim that may be made by its manufacturer, is not guaranteed or endorsed by the publisher.

Copyright (๑) 2022 Argunhan and Brain. This is an open-access article distributed under the terms of the Creative Commons Attribution License (CC BY). The use, distribution or reproduction in other forums is permitted, provided the original author(s) and the copyright owner(s) are credited and that the original publication in this journal is cited, in accordance with accepted academic practice. No use, distribution or reproduction is permitted which does not comply with these terms. 